\title{
Signaling Networks in Epithelial Tube Formation
}

\author{
Ilenia Bernascone, Mariam Hachimi, and Fernando Martin-Belmonte \\ Department of Development and Regeneration, Centro de Biologia Molecular Severo Ochoa (CSIC-UAM), \\ Madrid 28049, Spain \\ Correspondence: fmartin@cbm.csic.es
}

Epithelial tubes are crucial to the function of organ systems including the excretory, gastrointestinal, cardiovascular, and pulmonary. Studies in the last two decades using in vitro organotypic systems and a variety of animal models have substantiated a large number of the morphogenetic mechanisms required to form epithelial tubes in development and regeneration. Many of these mechanisms modulate the differentiation and proliferation events necessary for generating the cell movements and changes in cell shape to delineate the wide variety of epithelial tube sizes, lengths, and conformations. For instance, when coupled with oriented cell division, proliferation itself plays a role in changes in tube shape and their directed expansion. Most of these processes are regulated in response to signaling inputs from adjacent cells or soluble factors from the environment. Despite the great deal of recent investigation in this direction, the knowledge we have about the signaling pathways associated with all epithelial tubulogenesis in development and regeneration is still very limited.

$M$ any of our epithelial cells organize forming tubular organs (i.e., kidneys, lungs, mammary glands, and the vascular system), to perform fundamental body functions including gas exchange, excretion, and nutrient transport. Developmental programs comprising reiterative cycles of controlled branching events may explain the complex assemblies of "treelike-structured" organs such as the mammary glands. In contrast, "mesh-like structures," such as the vertebrate vascular system, requires also a process of tubular connection to generate the intricate networks (anatomoses) that are essential for the transport in the blood of nutrients, liquid, and air (Caviglia and Luschnig 2014). All epithelial tissues share common features, despite their morphological diversity. Epithelial cells can be organized into simple or stratified lay- ers, and their morphology can be classified into squamous, cuboidal, or columnar. Regardless of their different organizations, all epithelial cells are strongly packed, narrowly connected through cellular junctions, and highly polarized (Martin-Belmonte and Mostov 2008; McCaffrey and Macara 2011).

Most of the present knowledge of how tubulogenesis occurs in vertebrates is derived from 3D organotypic models, such as MadinDarby canine kidney (MDCK) cells and breast MCF10A cells, and endothelial cells, which have produced a large amount of information at a molecular and cellular level in the last 20 years (Shamir and Ewald 2014). However, many animals such as the Xenopus, zebrafish, and mouse are serving not only to confirm and validate this knowledge, but also to support a deeper under-

Editor: Keith E. Mostov

Additional Perspectives on Cell Polarity available at www.cshperspectives.org

Copyright (C) 2017 Cold Spring Harbor Laboratory Press; all rights reserved; doi: 10.1101/cshperspect.a027946 Cite this article as Cold Spring Harb Perspect Biol 2017;9:a027946 
I. Bernascone et al.

standing of the influence of other variables associated with tubulogenesis, such as relationships between the cells that form the epithelium and the stroma that surrounds them, which are more difficult to model using reductionist in vitro systems. In a broad sense, tubulogenesis involves the orientation of cells within their environment through cooperative cellular interactions, mainly those formed between cell-cell and cell-matrix: the development of apicobasal polarity, changes in cellular shape and movements, the formation and expansion of the luminal space, and finally, the fusion of these lumens to resolve them in a unique luminal cavity. Several reviews of tubule formation have described the molecular and mechanical control of these processes in different organs (Hogan and Kolodziej 2002; Lubarsky and Krasnow 2003; Bryant and Mostov 2007; Rodriguez-Fraticelli et al. 2011; Caviglia and Luschnig 2014; Sigurbjornsdottir et al. 2014). In this review, we will focus on the signaling pathways associated with the mechanisms of creating and elongating tubes from nonpolarized cells, as well as the signaling associated with tubular branching during development and regeneration in vertebrates.

\section{CREATING TUBES}

Epithelial tubes form during development by diverse mechanisms, which can be grouped into two types, depending on the degree of polarity of the originating cells (Hogan and Kolodziej 2002; Lubarsky and Krasnow 2003; Sigurbjornsdottir et al. 2014). Sheets of polarized cell generate hollow lumens through wrapping, folding, invagination, or evagination of these sheets. Nonpolarized cells can convert into polarized epithelial tubes and create lumens "de novo" between the cells, usually through a process of mesenchymal-epithelial transition (MET) (Thiery et al. 2009; Datta et al. 2011). Distinct mechanisms of de novo lumen formation both in vitro and in vivo share many common features and mechanistic similarities. Three mechanisms of de novo lumen formation have been described: cord hollowing, cell hollowing, and cavitation (Fig. 1), reviewed recently in Sigurbjornsdottir et al. (2014). Cord hol-
A

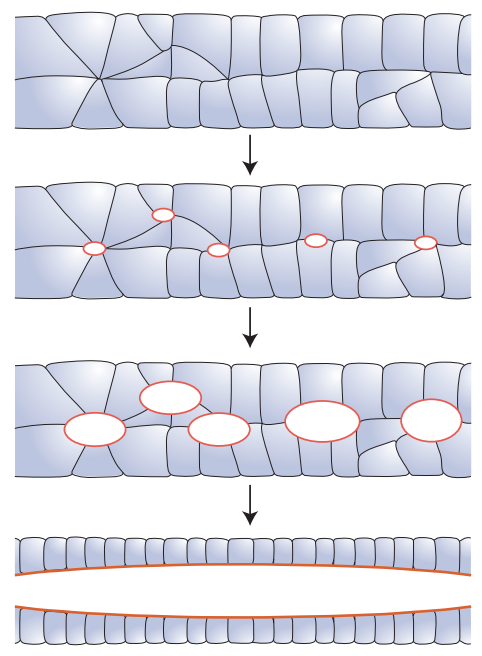

B

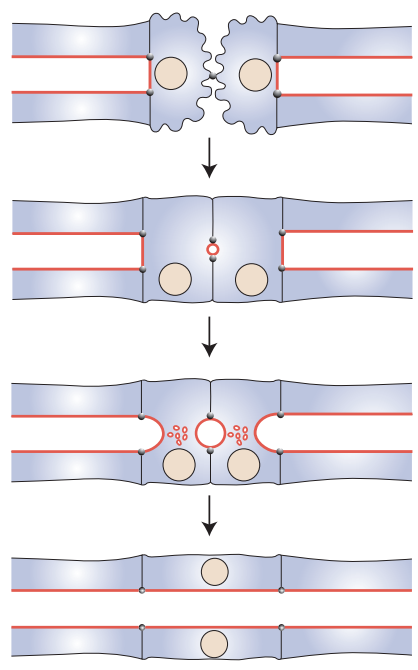

C
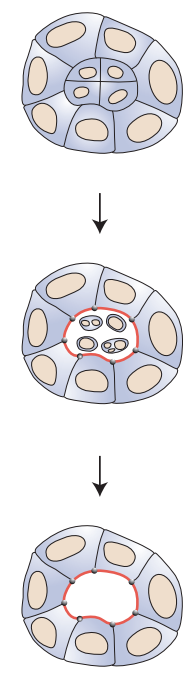

Figure 1. Mechanisms of de novo lumen formation: $(A)$ Cord hollowing is the appearance of a hollow space between two or more cells closely apposed. (B) Cell hollowing is the creation of a lumen within a cell. $(C)$ Cavitation is the process through which the death of cells at the center of multicellular assembly creates a hollow space. 
lowing (Fig. 1A) is the appearance of a hollow space between two or more cells closely apposed. A good example of cord hollowing is the formation of the zebrafish gut (Bagnat et al. 2007) and vasculature (Herwig et al. 2011). The creation of a lumen within a cell is called cell hollowing (Fig. 1B). The paramount models of cell hollowing can be found in invertebrates, Caenorhabditis elegans excretory cells and Drosophila tracheal cells (Sigurbjornsdottir et al. 2014). In vertebrates, cell hollowing was found in the formation of capillaries of the vasculature in zebrafish ( $\mathrm{Ka}$ mei et al. 2006; Herwig et al. 2011). Cavitation is the process through which the death of cells at the center of multicellular assembly creates a hollow space (Fig. 1C). An example of cavitation includes the clearance of the lumen by apoptosis in the terminal end bud (TEB) of the developing mammary gland (Humphreys et al. 1996). The signaling associated with tubulogenesis involves the integrin-mediated signaling associated with the orientation of polarity, which is mediated through cooperative cell-matrix interactions, the signaling mediated by the cell-cell adhesion complexes, and the signaling involved in the formation and expansion of the luminal space.

Signaling in the Orientation of the Apicobasal Polarity Axis

The establishment and orientation of the polarity axis is a key event during epithelial tubulogenesis. External cues provided by neighboring cells and the extracellular matrix are central regulators of the orientation of the polarity axis. These external cues, mediated by cell-cell, cellextracellular matrix (ECM), and intercellular junctions, induce signaling cascades that at the end modify the cell cytoskeleton, the trafficking machinery, cell contractility, and transcriptional response (Fig. 2). Our understanding of the steps involved in the generation of the epithelial axis derives mostly from studies performed in cultured epithelial cells, such as the 3D MDCK kidney and MCF10A mammary cells. The basement membrane $(\mathrm{BM})$ is a thin layer of ECM $(100 \mathrm{~nm})$ that contains a meshwork of laminins, collagen IV, proteoglycans, and nidogen. Cells can interact with the components of the
Signaling Networks in Epithelial Tube Formation

BM through cell-surface integrin receptors (Fig. 2A). Exposure of epithelial cells in suspension to collagen gels results in reorientation of polarity that depends on the $\beta 1$ integrin activation of the Rac 1 GTPase, and the assembly of a basement membrane via laminin secretion (O'Brien et al. 2001; Yu et al. 2005). However, downstream of $\beta 1$ integrins, not only Racl is involved; indeed, integrin-linked kinase (ILK) mediates the integrin-dependent polarization of microtubule plus ends at the basolateral membrane and promotes the orientation of polarity and development of lumens in mammary cells in 3D organotypic cultures and in vivo (Fig. 2A) (Akhtar and Streuli 2013). An interesting possibility could be that Racl and ILK act sequentially to promote orientation of polarity (Lee and Streuli 2014). Rac1 is required to correctly assemble laminin into a basement membrane downstream of collagen- $\beta 1$-integrin $(\alpha 2 \beta 1)$ interaction (O’Brien et al. 2001; Myllymaki et al. 2011) and perhaps in collaboration with the adaptor protein IRSp53. Indeed, MDCK cells lacking IRSp53 present reduced cell-matrix interactions and decreased laminin deposition (Cohen et al. 2011). Subsequently, $\beta 1$-integrin-mediated adhesion to basement membrane, likely mediated by $\alpha 3 \beta 1$ and $\alpha 6 \beta 1$ interaction with laminin, establishes the correct intracellular orientation of polarity through a distinct outside-in signaling pathway that involves ILK (Myllymaki et al. 2011; Akhtar and Streuli 2013). However, the involvement of ILK in other epithelial tissues is still unknown.

In vivo analysis showed also a specific requirement for $\beta 1$ integrin in laminin assembly and normal lumenogenesis in different mouse models (Wu et al. 2009; Zovein et al. 2010; reviewed in Lee and Streuli 2014). Interestingly, recent results have also showed that this mechanism for the orientation of polarity axis is also essential for the acquisition of polarity in early embryos both in vivo and in vitro (Bedzhov and Zernicka-Goetz 2014). The pluripotent epiblast (EPI), a ball of cells positioned in the inner cell mass (ICM) of the blastocyst, whose identity is established during the first 4 days of development, becomes organized into a rosette-like structure of highly polarized cells with a central 
I. Bernascone et al.

A Orientation of polarity

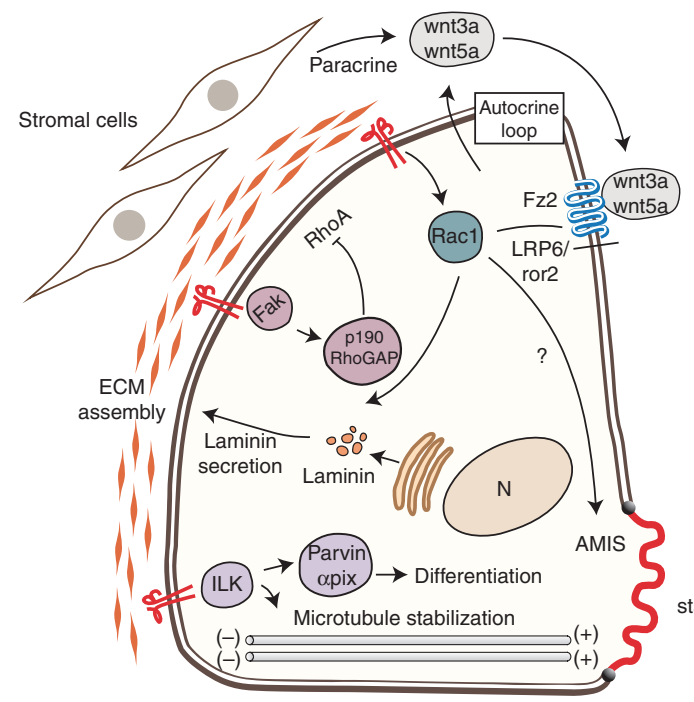

B Lumen initiation

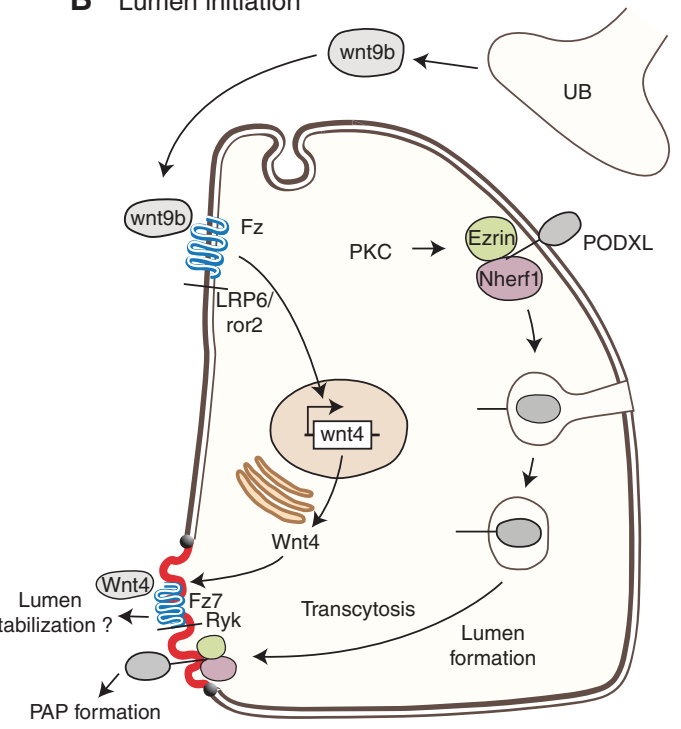

C Lumen signaling
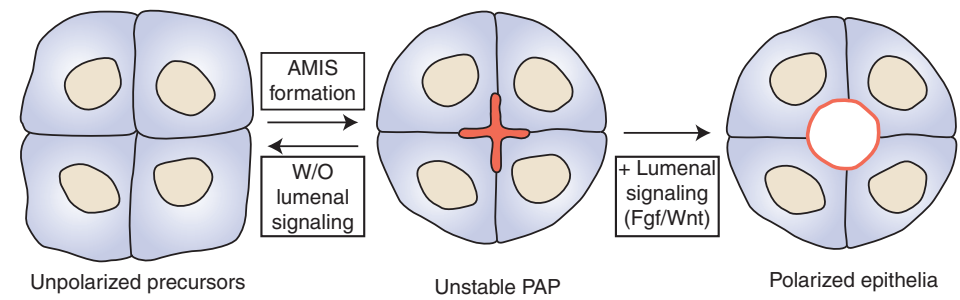

Figure 2. Signaling pathways associated with de novo lumen formation. (A) Integrin-mediated signaling in the orientation of polarity, $(B)$ integrin-mediated and Wnt signaling in lumen formation, and $(C)$ lumen signaling might induce the epithelial program in the formation and expansion of the luminal space.

lumen. This is orchestrated by polarization cues from the basal membrane transmitted through $\beta 1$ integrin receptors (Bedzhov and ZernickaGoetz 2014). Moreover, in the same study, the investigators showed that the formation of embryonic lumen does not depend on cavitation mechanisms, as previously thought based on experiments performed with embryonic bodies (EBs), but is formed instead by lumen hollowing. Apparently, the difference lies both in the cell number and in the timing of this process: on the first day of culture, there are usually a few hundred cells in an EB that need 4-7 days to establish polarized epithelium and to cavitate, whereas the EPI of the blastocyst is composed of $8-16$ cells at the onset of implantation and polarize in $24 \mathrm{~h}$ (Bedzhov and Zernicka-Goetz 2014). This might explain why EBs initiate formation of multiple cavities in contrast to the embryo, where only a single lumen emerges at the center of the rosette of EPI. This extended time required for cell polarization may trigger an apoptotic mechanism for cavity formation. Indeed, such apoptosis-driven cavitation is also seen in MDCK cells polarizing slowly when grown in the absence of strong polarization cues, whereas they form single central lumens within 2 days and independently of apoptosis when they polarize efficiently (Martin-Belmonte et al. 2008). Therefore, epithelial cells both in vivo and in organotypic 3D cultures are able to shift their mechanisms of de novo 
lumen formation, depending on the efficiency of cell polarization, suggesting that the timing of self-organization of 3D cultures in ECM appears to be very close to physiological events.

\section{Wnt Signaling in the Orientation of Polarity}

Studies in the last decade have shown that Wnt ligands and their receptors are secreted in epithelial cells in a polarized fashion. Wnt5a and Wnt3a are secreted through the basolateral domain, as well as their specific receptors Fz2 (Wnt5a and Wnt3a), LRP6 (Wnt3a), and Ror2 (Wnt5a), using clathrin-coated vesicles and AP1 (Yamamoto et al. 2013, 2015), which are common machineries for the basolateral sorting of membrane proteins (Rodriguez-Boulan and Macara 2014). Similarly, Ror2 and LRP6 distribute to the basolateral membranes of the embryonic midgut epithelium and outer ectodermal cells, respectively (Yamada et al. 2010; Huang and Niehrs 2014). By contrast, Wnt11 is secreted apically through glycan-mediated signals (Yamamoto et al. 2013), whereas its receptors Fz7 and Ryk localized both at the apical and basolateral membranes (Yamanaka and Nishida 2007; Kim et al. 2008). Wnt receptors are thus sorted to the same polarized domains as the corresponding Wnts, thereby leading potentially to an efficient autocrine activation of the Wnt pathway. In the basal region of embryonic midgut, the primary source of Wnt5a secretion are the mesenchymal cells, so that epithelial cells expressing Wnt5a receptors (Fz2/Ror2) at the basolateral membranes might receive Wnt5a secreted by mesenchymal cells, suggesting a paracrine signaling in other systems.

Is this polarized secretion of Wnts, and their receptors, functionally coupled to the acquisition of polarity and the formation of the lumens in epithelial tubes? In 3D organotypic cultures of MDCK and IEC6 cells, the Wnt5a-Fz2-Ror2 pathway seems to be involved in the establishment of epithelial polarity. Basolateral polarized secretion of Wnt5a stimulates, very likely through Ror2/Fz2, the adhesion-dependent Rac activation, the acquisition of apical/basal polarization, and the formation of the apical lumen, thereby promoting lumen formation in an
Signaling Networks in Epithelial Tube Formation

autocrine manner (Yamamoto et al. 2015). Furthermore, Ror2-knockout embryonic gut epithelial cells show aberrant clumps, which suggests polarity loss and random orientation of cells (Yamada et al. 2010). In summary, epithelial cells secrete by specific sorting mechanisms Wnt5a receptors to the basolateral side, where they bind to Wnt5a ligand, acting through either paracrine or autocrine mechanisms, and this activation is necessary for epithelial tubulogenesis.

Very little is still known about the role of Wnt signaling in epithelial polarity and tubulogenesis in vivo (Karner et al. 2006). Interestingly, the onset of apicobasal polarity matches the epithelialization of cap mesenchymal cells that gives rise to the renal vesicles in nephrogenesis (Marciano 2016). The Wnt signaling pathway is known to regulate this epithelialization process. The kidney consists of numerous epithelial tubes, known as nephrons, connected to the collecting duct system. These two types of tubules derive from distinct structures. During vertebrate embryonic development, an epithelial structure called the ureteric bud (UB) invades the metanephric mesenchyme (MM) and undergoes repetitive branching to give rise to the collecting duct. The MM surrounding each UB tip undergoes a MET forming the renal vesicle that will develop into the C- and S-shaped bodies (Costantini and Kopan 2010). These structures will give rise to the mature nephron by a program of segmental differentiation and elongation. Wnt9b, secreted from the UB epithelium, can trigger differentiation of the MM by inducing expression of Wnt4 in pretubular aggregates (Karner et al. 2009). Afterward, Wnt4 secretion by pretubular aggregates, presumably in an autocrine loop, is both necessary and sufficient to control their progression to renal vesicles (Stark et al. 1994; Kispert et al. 1998). However, how Wnt 4 signaling induces this epithelialization process of the pretubular aggregates is still under debate, but a clear possibility is through the control of cell polarity.

\section{Signaling in Lumen Formation}

Once the cell has oriented the polarity and the apical/basal polarization is promoted, external 
I. Bernascone et al.

cues act together with polarity proteins, lipids, and Rho GTPases to form the cellular junctions and to organize the molecular trafficking necessary to form apical and basal domains. Most of the current knowledge that we have about these signaling and trafficking mechanisms is derived from work performed in organotypic cultures (Eaton and Martin-Belmonte 2014). Indeed, the integrin signaling network is necessary for the endocytic removal of apical proteins from the basement membrane-cell interface, their delivery to the correct surface by trancytosis, and the formation of the lumen de novo (Bryant et al. 2010; Apodaca et al. 2012; GalvezSantisteban et al. 2012; Akhtar and Streuli 2013). One of the most essential effects downstream of integrins-ECM signaling in epithelial and endothelial lumen formation is the suppression of RhoA activation at the cell-ECM interface (Ferrari et al. 2008; Yu et al. 2008; Rodriguez-Fraticelli et al. 2012). Furthermore, recent work has showed that integrin-dependent activation of focal adhesion kinase (FAK), mediated by $\alpha 2 \beta 1$ and $\alpha 3 \beta 1$, and FAK-dependent phosphorylation of p190A RhoGAP led to inactivation of RhoA/Rho kinase at the ECM interface (Fig. 2A). Then, PKC $\beta I I$ and PKC $\alpha$ cause phosphorylation-dependent dissociation of podocalyxin/NHERF1/ezrin complexes at the basal membrane, which is crucial for podocalyxin translocation to the apical domain, and the reformation of Podxl/NHERF1/Ezr complexes during apical membrane assembly in a protein phosphatase $2 \mathrm{~A}$ (PP2A)-dependent manner (Fig. 2B) (Bryant et al. 2014). Thus, cells interpret the cues from the surrounding environment to mainly biosynthesize new membranes and polarize the trafficking machinery to take them toward the newly formed apical pole. Next, epithelial tubes need to initiate and stabilize the lumen. During MDCK cysts formation, the lumen is originated from one or multiple preapical patches, microdomains of the plasma membrane that contain apical polarity proteins such as podocalyxin, Par-3, or Crbs (Ferrari et al. 2008; Bryant et al. 2010). These preapical patches are usually formed between two or more cells, lack basolateral membrane proteins, and organize in rosette- like structures that precede the formation and expansion of a single lumen. Recently, it has been shown that renal pretubular aggregates form preapical domains, analogous to the preapical patches of 3D MDCK cysts, before coalescence to form rosette-like structures and single lumens in renal vesicles of nephron progenitors (Yang et al. 2013). Also, this mechanism of lumen formation may resemble the tendency of ICM of the blastocyst to generate rosette-like structures and single lumens in vivo (Bedzhov and Zernicka-Goetz 2014; Meinhardt et al. 2014).

The formation of a central lumen seems to be a self-organizing property of many cell types, such as epithelial, endothelial and embryonic stem cells. This special feature allows the fascinating hypothesis of the existence of a luminal signaling to provide a potential mechanism to locally limit, synchronize, and increase communication between cells. An interesting work has been recently published by Gilmour and collaborators (Durdu et al. 2014), using as a model the collectively migrating epithelial lateral line primordium, in which rosette-like mechanosensory organs are assembled and deposited along the flanks of the embryo during zebrafish development (Haas and Gilmour 2006). The investigators show that fibroblast growth factors (FGFs) signaling, which regulates the epithelialization of the deposited rosettes (Lecaudey et al. 2008), becomes specifically concentrated in microluminal structures that assemble at the center of these organs and spatially constrain its signaling activity to control the frequency of deposition of these organs. Furthermore, FGF signaling in this microlumina increase signaling responses in these cells, thus allowing FGF to coordinate the migratory behavior of cell groups in the primordium (Fig. 2C) (Durdu et al. 2014).

The obvious question is whether this luminal signaling found in neuromast precursors is a more general process required in any context in which cells construct a lumen, as in epithelial tubulogenesis. If so, at early stages, the formation of the microlumens in the preapical patches could restrict, coordinate, and enhance luminal signaling within the rosette-like structures. 
This local increase in luminal signaling might then feed back on the microlumens by increasing the epithelialization and differentiation of responding cells, leading to the formation of stable lumens. Thus, luminal signaling might provide a checkpoint during development to ensure that cells become polarized and organized, before they can efficiently respond to signals stimulating their differentiation. Moreover, as lumen formation itself is highly sensitive to changes in epithelial polarity, adhesion and ECM composition (Martin-Belmonte et al. 2008; Bryant et al. 2014), it is likely that luminal signaling might adapt to processes that modify cell behavior, such as the EMT/MET, which are hallmarks of normal development and cancer (Fig. 2C). In fact, Wnt4, which is a well-known inducer of epithelialization in the conversion of pretubular aggregates to renal vesicles, is secreted apically in 3D MDCK cells at early stages of lumen formation (I Bernascone and F MartinBelmonte, unpubl.), implying that it might induce luminal signaling during nephron morphogenesis. Favoring this hypothesis, a recent single-cell RNA-seq analysis shows stochastic expression of various genes within nephron, with only one to a few individual nephron progenitor cells expressing Wnt4 in the developing kidney (Brunskill et al. 2014). Therefore, very low levels of expression of Wnt 4 might require the small space found in the preapical lumens to efficiently induce epithelialization in these precursors. Furthermore, a recent work has showed that Endoglycan, a CD34 family member with homology with podocalyxin, localize to large, intraluminal structures that may be vesicles/ exosomes (Yang et al. 2016). These vesicles might be required for intercellular communication (luminal signaling) to drive nephron differentiation and/or extend the lumen to adjacent cells in vivo. They may also serve to regulate the size of the apical domain. Indeed, lumen expansion involves the structured expansion of the apical plasma membrane and the lumen through general mechanisms of vesicle transport, microtubule and actin cytoskeleton regulation, and the regulated activity of hydrostatic pressure (Datta et al. 2011; Rodriguez-Fraticelli et al. 2011; Apodaca et al. 2012; Rodriguez-Bou-
Signaling Networks in Epithelial Tube Formation

lan and Macara 2014; Sigurbjornsdottir et al. 2014; Navis and Bagnat 2015). Additionally, it is also possible that an apical ECM (aECM) might contribute to define the final morphology of biological tubes in vertebrates, as has been found in invertebrates (Devine et al. 2005). This aECM seems to have essential roles in cell signaling and their mechanical response that influence the stability and final morphology of biological tubes (Forster and Luschnig 2012; Dong et al. 2014; Ozturk-Colak et al. 2016)

\section{ELONGATING TUBES}

\section{Cell Intercalation and Cell Division}

The elongation of tubes can occur through several cellular mechanisms. Due to the purpose of this review, we will not describe processes like cell-shape change and cell recruitment that are typical of Drosophila salivary gland/trachea and Malpighian tubules, respectively. We refer the reader to excellent papers on these topics (Bradley et al. 2001; Denholm and Skaer 2003; Jung et al. 2005). Here we focus on the processes driving tubule elongation in distinct vertebrate tubular organs, including convergent extension (CE) and cell division.

CE is a highly regulated process that, by driving change in cell position in an epithelial monolayer, leads to tissue narrowing (convergence) along its mediolateral axis and concomitant elongation (extension) along its anteroposterior axis. The first identified example of $\mathrm{CE}$ in development is body axis elongation during gastrulation (Keller et al. 2000), in which germ layer progenitor cells move toward the dorsal side of the gastrula, where the embryonic axis will form and, concomitantly, cells intercalate along their axis of movement. Therefore, $\mathrm{CE}$ includes two types of cell rearrangement: cell intercalation and collective cell migration. In cell intercalation, cells redistribute their position and exchange neighbors in the anteriorposterior axis of the tissue (Fig. 3). Oriented cell division (OCD), which is controlled by the orientation of the mitotic spindle (Gillies and Cabernard 2011), has also been proposed to contribute to tubular elongation (Fig. 3). 
I. Bernascone et al.
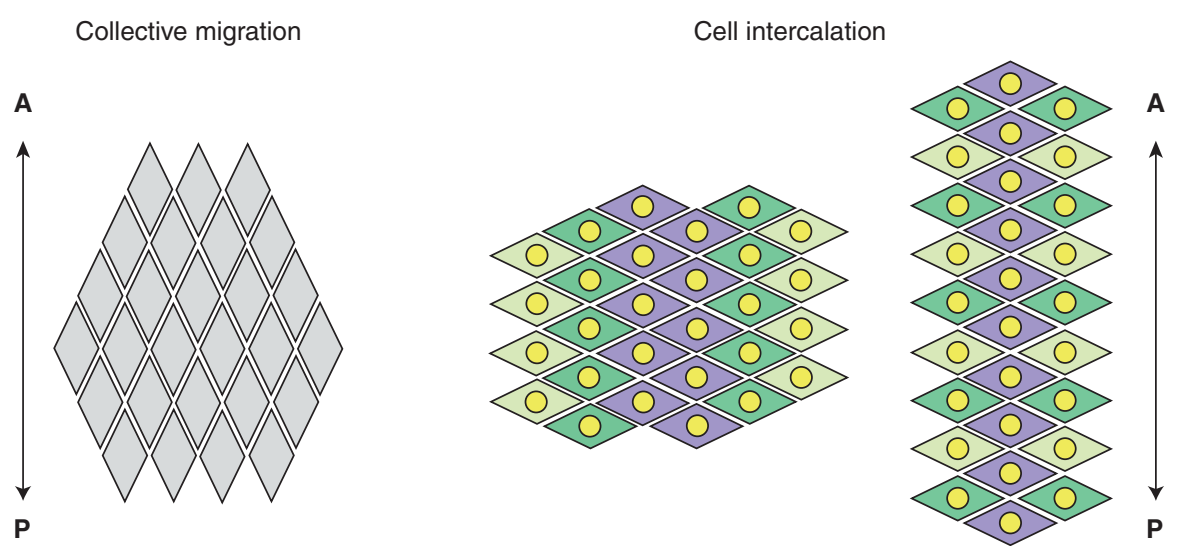

Figure 3. Convergent extension is driven by two different types of cell movement. In collective migration (left), cells migrate as a cohesive sheet and do not exchange neighbors. In cell intercalation (right), cells redistribute their positions and exchange neighbors. The arrows indicate the direction of cell movement. A, Anterior; P, posterior.

The main signaling pathway that has been shown to direct cell intercalation and cell division is planar cell polarity (PCP). First we will describe the major components of the PCP pathway, then we will review the data showing a role of PCP in the elongation process in the kidney and neural tube.

\section{Planar Cell Polarity}

Planar cell polarity, also known as tissue polarity, is defined as the organization of cells in the plane of a tissue that is perpendicular to the apicobasal axis. PCP was first described in Drosophila eye and wing imaginal disc (Adler 2002). Genetic and molecular studies have revealed three major groups of PCP genes. The first group is the "core module" and it consists of six core proteins, including Frizzled (Fz), Dishevelled (dsh), Diego (dg), Van Gogh (vang), Flamingo ( fmi), and Prickle ( $p k)$. These proteins coordinate polarity locally between adjacent cells. In the fly wing imaginal disc, vang and $p k$ accumulate at the proximal side, whereas $F z$, $d s$, and $d g$ accumulate at the distal side (Zallen 2007). Fmi is localized to both sides. The second PCP group is the Fat/Ds PCP group, and it is composed of the large atypical cadherins fat and dachsous (ds), and the Golgi-associated protein four-jounted ( $f j$ ) (Axelrod 2009). Since the op- posing expression gradients of $d s$ and $f j$ are thought to provide global polarity with regard to the axes of the entire tissue, this group is known as the "global module." Downstream of the core PCP genes and the Fat/Ds system are tissue-specific PCP effectors that convert PCP signals into the corresponding cellular response, thus regulating polarity at the level of individual cells (Wang and Nathans 2007).

Many vertebrate tissues and developmental processes have been shown to display typical PCP features (Fanto and McNeill 2004; Goodrich and Strutt 2011). Although gene redundancy and protein functional compensation hamper the study of PCP in vertebrates, mutation and overexpression studies performed in the last years have revealed that many of the proteins linked to PCP in fly are evolutionarily conserved and have analogous roles and similar asymmetric localization in vertebrates. The principal signaling pathway related to PCP appears to be the "noncanonical" Wnt signaling in which binding of secreted Wnt ligands to a Fz receptor activates small GTPases, including Rho, Rac, and Cdc42 and downstream kinases such as JNK or Rho kinase, eventually leading to actin cytoskeleton rearrangements and coordinated polarization of cells resulting in PCP (Rao and Kuhl 2010). For this reason, the "noncanonical" Rho/JNK pathway is frequently referred to as the PCP 
pathway. Whether the Wnt pathway plays a role in PCP in Drosophila is still controversial.

Another possible vertebrate-specific PCP regulator is the protein tyrosine kinase 7 (PTK7), an evolutionarily conserved transmembrane protein with tyrosine kinase homology, which has been shown to play a role either dependent or independent of the Wnt pathway (Peradziryi et al. 2012). Furthermore, the primary cilium has emerged as a specific PCP regulator. Components of the core PCP machinery, such as Fz, Vangl, Dvl, and Inversin (homolog of Drosophila Diego), are localized in the basal body. Mice with mutations in genes necessary for ciliogenesis show pathologies that have been linked to PCP defects (Wallingford and Mitchell 2011). At present, the developmental events in vertebrates that have been described to be under control of the PCP genes involve epithelial and nonepithelial cells (Wang and Nathans 2007). Below we will focus on vertebrate epithelial processes that participate in tubular organogenesis in which there are evidences for PCP activity.

\section{PCP in Kidney}

Recent studies have revealed that PCP signaling has an important role in normal kidney devel-
Signaling Networks in Epithelial Tube Formation

opment. Works performed in the last 10 years have shown that elongation of renal tubules is achieved through two distinct processes occurring in two distinct developmental phases: during embryonic development, a process of CE driving cell intercalation allows the tubule to become longer and narrower without changing cell number; postnatally, oriented cell division (OCD) along the longitudinal axis of the tubule allows to maintain the correct diameter and to increase the tubule length (Fig. 4) (Karner et al. 2009). Regarding OCD, it was originally hypothesized that tubule elongation requires a preferential displacement of pairs of daughter cells along the longitudinal axis of the tubule, and that cyst formation arises from abnormal transverse orientation of pairs of daughter cells (Germino 2005). By elegant studies, Fischer et al. showed that there is a high degree of oriented cell division in the outer medullary tubules, with $95 \%$ of cells dividing within $34^{\circ}$ of the axis of the tubule (Fischer et al. 2006). Interestingly, in the same paper, the investigators show that in different rat and mouse models of cystic kidney disease oriented cell division is lost and, in this context, tubules become extremely dilated (Fischer et al. 2006). The demonstration that PCP controls OCD
A

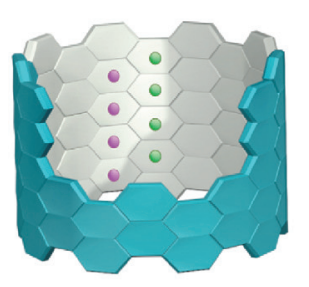

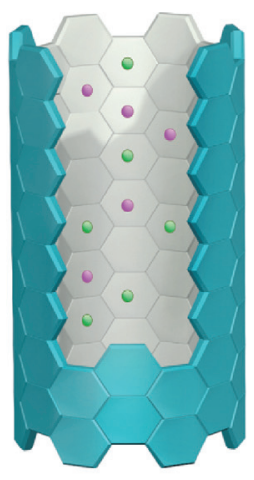

B

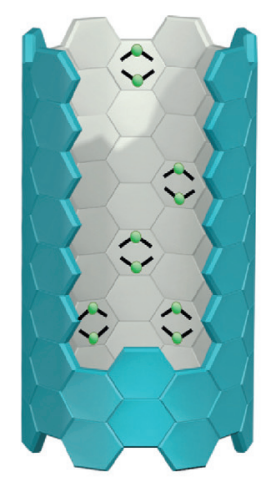

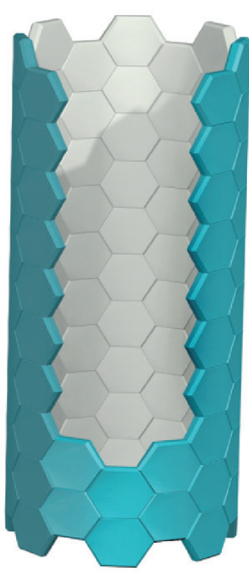

Figure 4. Narrowing and elongation of renal tubules. (A) During embryonic development, cells intercalate perpendicularly to the longitudinal axis, so that the tubule becomes narrower and longer without cell proliferation. (B) Postnatally, cells orient their mitotic spindles parallel to the proximodistal axis, thus maintaining the established tubule diameter and allowing the tubule to elongate. 
I. Bernascone et al.

came up later, by the generation and characterization of PCP mutant mice. Fat4 mutant kidneys display a randomization of spindle orientation, with consequent loss of OCD, and they show dilated tubules and cysts (Saburi et al. 2008). In Vangl2 mutant mouse kidneys are shorter, occasionally dilated, and with less glomeruli in comparison to wild-type animals, thus showing that a PCP gene is required for normal morphogenesis of both the UB and metanephric-derived structures (Yates et al. 2010). Furthermore, Dchs1 and Fat4 double mutants display decreased branching and reduced size of the kidney, thus showing the involvement of PCP genes in the survival of kidney epithelial cells and in the proliferation of epithelial and mesenchymal cells (Mao et al. 2011).

Only recently imaging of $\mathrm{CE}$ has been achieved in vertebrates in living conditions (Lienkamp et al. 2012). In Xenopus laevis, kidney tubule elongation has been fascinatingly imaged in vivo and shown to occur via multiple rounds of cell intercalations that use the formation of a rosette-like structure, a mechanism previously described only in Drosophila germ band. These data confirm that the multicellular rosettes that investigators have been observing until that moment in fixed tissues from Xenopus and mouse are dynamic structures, and they suggest CE might be a well-conserved mechanism among vertebrates (Lienkamp et al. 2012; Castelli et al. 2013). Furthermore, in Xenopus nephron, a link between PCP and cell intercalation has been unambiguously shown. Inhibition of PCP by expression of a PCP-specific dominant-negative form of Dishevelled 2 causes a dramatic reduction in nephron elongation and a corresponding increase in tubule diameter and number of cells spanning the tubule circumference, phenotypes accompanied by a disruption of rosette topology and orientation of multicellular rosettes. At the molecular level, actomyosin-mediated shrinkage of vertical junctions is essential for rosette formation in Xenopus kidney, as it is in Drosophila germ band, and PCP signaling seems to control myosin II (Lienkamp et al. 2012).

Several Wnts family members are expressed in kidney and at least some of them have been shown to be effectors of PCP. For example, Wnt9b is expressed in the stalks of the collecting ducts and it is necessary for CE and OCD. In $W n t 9 b$ mutant kidneys elongation of cells is randomized during the embryonic period and orientation of cell division is lost postnatally (Karner et al. 2009). Wnt9b is likely to regulate PCP through a noncanonical pathway, because decreased levels of activated Rho and Jnk2 were found in Wnt9b mutant kidneys. Interestingly, Wnt9b expression in the collecting ducts appears to be directly regulated by Hnflb, at least partially explaining the PCP defects in Hnflb mutants (Fischer et al. 2006). It is to note that in Wnt9b mutant kidneys cysts arise in both the collecting duct (Wnt9b-expressing tissue) and the remaining nephron segments (not expressing Wnt9b), thus showing that Wnt9b acts on PCP via a nonautonomous mechanism.

Similarly to Wnt9b, the expression of Wnt7b is restricted in the kidney collecting duct system. In the absence of Wnt7b, the renal medulla fails to form and this phenotype reflects improper orientation of cell division and consequent defect in the elongation of the renal tubule. Wnt7b appears to signal to the adjacent stromal cells through the canonical pathway (Yu et al. 2009).

\section{PCP in Neural Tube}

During neurulation, the neural plate elongates and forms a central groove, which subsequently folds and closes to create the neural tube. The role of PCP in neural tube closure was initially shown in Zebrafish and Xenopus. In Zebrafish, mutations of vangl2 and prickle disrupt CE (Jessen et al. 2002; Veeman et al. 2003). In Xenopus, Dishevelled protein has been shown to control CE in neural tube closure (Tada and Smith 2000; Wallingford et al. 2000; Wallingford and Harland 2002). In mice, inactivation of Vangl2 (Greene et al. 1998), Celsr1 (orthologue of fmi) (Curtin et al. 2003), or the simultaneous loss of both Dvl1 and Dvl2 (Wang et al. 2006a) and of both Fzd3 and Fzd6 (Wang et al. 2006b) lead to a completely open neural tube, a phenotype known as craniorachischisis, attributed to a defective cell intercalation. Also, PTK7 has been 
shown to be required for neural CE and neural tube closure in mouse and Xenopus (Lu et al. 2004). Interestingly, Ciruna et al. (2006) show that PCP participates not only in CE but also in OCD in Zebrafish neurulation. They show that loss of Zebrafish Vangl2 abolishes the polarization of neural keel cells, disrupts the reintegration of newly postmitotic cells into the neuroepithelium from which they have been transiently extruded, and results in ectopic neural progenitor accumulations and neural tube defects (NTDs). Remarkably, blocking cell division leads to a rescue of NTDs despite persistent defects in CE. These results reveal a role for PCP signaling in coupling cell division and morphogenesis during the neurulation process. Until now, the relationship between PCP and OCD in mammalian neural tube closure has not been uncovered.

\section{Collective Cell Migration}

In collective migration, cells do not intercalate but they migrate as a cohesive cluster or sheet.

Zebrafish kidney is a very interesting example of tube elongation driven by cell migration. Taking advantage of its simplest structure (it contains two nephrons only) in comparison to vertebrates, living imaging has shown that pronephric cells actively migrate toward the glomerulus extending lamellipodia from their basal surface while maintaining apical polarized connections with the neighboring cells, a common feature of collective cell migration (Vasilyev et al. 2009). The process of cell migration defines the final position of nephron segment boundaries and convolution of the proximal segment, and it is dependent on fluid flow. Cell migration is coupled to and stimulates epithelial cell proliferation in the distal tubule, which in turn is required to support proximal migration by replacing migrating cells. It has been shown that cell proliferation is dependent on PI3K signaling and it is likely to be signaled by cell stretch (Vasilyev et al. 2009, 2012). It is not known whether PCP controls collective cell migration. In the chick embryo, FGF signaling is required for nephric duct migration but it alone is not sufficient to determine the direc-
Signaling Networks in Epithelial Tube Formation

tion of the migration (Attia et al. 2015). Furthermore, collective cell migration has been observed in an in vitro model of mammary branching (Ewald et al. 2008). In elongating mammary ducts, luminal cells advance collectively without any cellular extrusion. Ductal initiation requires Rac and myosin light-chain kinase, whereas repolarization to a bilayer depends on Rho kinase.

\section{BRANCHING MORPHOGENESIS}

Branching morphogenesis is a common process in animal organogenesis. It is the developmental program that builds the arborized networks of various organs, including the vascular system, the airways of the lung, the collecting ducts of the kidney, and the secretory ducts of the mammary gland (Ochoa-Espinosa and Affolter 2012). Branched tubular systems share some common anatomical features. All of them are hierarchical (i.e., the new tubes arising from preexisting ones by repeated rounds of sprouting have gradually reduced diameter). Furthermore, branched organs are composed of only two types of cells, either endothelial or epithelial cells. The morphological similarity between the tubular systems suggested that a conserved set of regulatory programs control branching morphogenesis. The studies performed in the last 40 years, and that benefited from the evidences collected from the analysis of Drosophila tracheal system, reveal that branching morphogenesis in vertebrates is controlled by conserved signaling pathways, including Wnt, FGF, Sonic Hedgehog (Shh), TGFß/BMP, and epidermal growth factor (EGF) signaling. In the sections below, we will sum up the published literature illustrating how these pathways act in different organs. The scenario that emerges is that in all tubular organs branching is controlled by the combined action of two pathways, one promoting and one inhibiting branching, generating a negative feedback loop. For example, such a link exists in the lung between FGF and SHH pathways, the first activating and the last restricting airway branching.

While signaling pathways are well characterized in terms of extracellular ligands and bind- 
I. Bernascone et al.

ing receptors, little is known about their target genes/molecules inside cells. Intracellular signal transduction pathways still need to be unraveled. Remarkably, pioneering studies in the 1960s revealed that branching also depends on interactions between the epithelium and the surrounding mesenchyme (Grobstein 1967). Grafting techniques showed that the lung mesenchyme could induce lung-like branching morphogenesis in the tracheal epithelium and in the UB of the kidney (Alescio and Cassini 1962; Lin et al. 2001). It is clear now that in the mouse lung important patterning information is exchanged between the epithelial and the mesenchymal components (Warburton et al. 2000). Similarly, nephrogenesis depends on the communication between the UB and the MM (Costantini and Kopan 2010) and in the mammary gland there is a clear coordination between epithelial and stromal cells (Ingman et al. 2006).

\section{Wnt Signaling}

The Wnt signaling pathway has been implicated in multiple aspects of both embryonic and postnatal mammary gland development. The mammary gland is organized into a tree-like structure and it is one of the few organs that undergo most of its development postnatally. Epithelial duct structures comprise an internal layer of cells surrounding a central lumen, referred to as luminal cells, and an outer basal layer of cells, containing myoepithelial and stem/progenitor cells. During puberty, female ovarian hormones (essentially estrogen) induce ductal elongation and secondary branching by stimulating proliferation from terminal end buds (TEBs) of the ducts. During pregnancy, a process of tertiary branching takes place, stimulated by hormones such as progesterone and prolactin, accompanied by alveolar differentiation.

Two mammary tissue transcriptomic analyses performed in the last years identified Wnt ligands as candidate regulators of mammary branching (Weber-Hall et al. 1994; KourosMehr and Werb 2006). Interestingly, what arises from these studies is that Wnt ligands are differentially regulated during the different phases of mouse mammary gland development (Gavin and McMahon 1992; Buhler et al. 1993; Weber-Hall et al. 1994). Genes that are strongly expressed in virgin glands, like Wnt-2, Wnt$5 \mathrm{a}$, and Wnt-7b, are down-regulated in pregnancy, suggesting that they act as inhibitors of branching. By contrast, the expression of Wnt4 , Wnt-5b, and Wnt-6 is strongly induced during pregnancy, evoking their role as stimulators of branching (Weber-Hall et al. 1994). The action of Wnt ligands has also been investigated in different mouse models. Retroviral expression of Wnt-7b did not alter mammary gland development (Naylor et al. 2000). By contrast, the absence of Wnt-5a accelerated mammary development, marked by larger terminal end buds, rapid ductal elongation, and increased side branching (Roarty and Serra 2007). Overexpression of Wnt4 induces an increase in branch density in virgin females (Bradbury et al. 1995), similar to that seen during pregnancy. Consistent with that, knockdown of Wnt 4 causes a delay in ductal branching in recipient mice transplanted with Wnt4 knockout mammary cells during pregnancy (Brisken et al. 2000). Wnt4 is the only Wnt ligand directly controlled by progesterone. All of these results suggest that Wnt signals have distinct effects on mammary growth and that a correct balance between positive and negative Wnt signals is necessary for the proper development of mammary tissue.

In the lung, both canonical and noncanonical Wnt pathways are required for branching morphogenesis. The developing lung extends into the surrounding mesenchyme and undergo rapid branching morphogenesis that is crucial for generating the highly arborized airway tree. Reduction in canonical Wnt $/ \beta$-catenin signaling in the pulmonary epithelium results in enlarged bronchioles with a reduction in epithelial branches and alveoli (Mucenski et al. 2003).

The most extensively studied noncanonical Wnt ligand is Wnt5a. Wnt5a is expressed in both lung mesenchyme and epithelium, but becomes restricted to the distal epithelium after E12.5. Wnt5a knockout mouse shows overproduction of peripheral airways and attenuated 
lung maturation ( $\mathrm{Li}$ et al. 2002). Wnt5a transgenic lungs show an opposite phenotype, including reduced branching and early onset of distal airways (Li et al. 2005). Wnt5a regulates branching via regulation of Shh protein expressed by the epithelium, which in turn regulates FGF10 signaling in the mesenchyme (see paragraph below) (Li et al. 2005). As anticipated before, these types of interactions between epithelium and mesenchyme are essential for lung branching morphogenesis.

\section{FGF Signaling}

Both in vivo and in vitro studies point to FGFs as an important class of growth factors for UB branching, especially FGF7 and FGF10. There are four FGF receptors in mammals, FGFR1 to FGFR4. FGFR1, 2, and 3 have two receptor isoforms (termed IIIb or IIIc) that are generated by alternative splicing, and each binds to a specific group of FGF ligands. FGF7 and FGF10 mRNAs are detected in the developing rat and mouse renal stroma (Cancilla et al. 1999; Qiao et al. 1999). Both FGFs bind to FGFR2-IIIb (FGFR2b), which is mainly expressed in the UB epithelium (Qiao et al. 2001). FGF7 knockout kidneys show a smaller collecting system size and a reduced nephron number in comparison to wild-type kidneys (Qiao et al. 1999). Treatment of cultured kidney rudiments with exogenous FGF7 leads to an increase of the size of the UB compartment, as well as of nephron number (Qiao et al. 1999). FGF10 null kidneys are also smaller, with dysplasia of outer medulla (Ohuchi et al. 2000). FGF10 applied to cultured whole rat kidney induces the formation of branched tubular structure composed of stalk and distinct ampullae (Qiao et al. 2001). The important role of FGFs in UB branching was confirmed by the analysis of mouse models for FGFR2b. Transgenic mice expressing a soluble dominant-negative form of FGFR2b display agenesis or severe dysgenesis of the kidney (Celli et al. 1998). Furthermore, in an UB-specific knockout mouse model of FGFR2, kidneys are significantly smaller than normal, with reduced UB branching and reduced nephron number (Zhao et al. 2004).
Signaling via FGFs is also a major pathway for branching morphogenesis in the mammary gland. Only FGFR1 and FGFR2 have been found to be expressed in TEBs (interior body cells and surrounding cap cells) and in the luminal epithelium of mammary gland from pubertal and adult females (Lu et al. 2008). Most of the studies have been focused on FGFR2, whereas little is known about the role of FGFR1 in mammary branching morphogenesis. In mice expressing an FGFR1 floxed allele and a Cre-recombinase under expression of the keratin 14 promoter, a delay of mammary gland development has been observed at 3 and 5 weeks of age, consisting of a reduction in ductal outgrowth and branch points, together with a decrease of cellular proliferation. This phenotype was transient and it was lost by 7 weeks of age (Pond et al. 2013). The same study shows that conditional depletion of both FGFR1 and FGFR2 on mammary epithelial cells, using limiting dilution transplantation analysis, resulted in an inhibitory outgrowth of the mammary gland (Pond et al. 2013). Other studies show that inducible depletion of FGFR2b is sufficient to generate an incomplete branching structure with no TEBs (Parsa et al. 2008). Recent studies elucidate the role of FGFR2 in controlling the differentiation of mammary basal cells to luminal cells because of the binding of its ligands FGF2 and FGF10. fgfr 2 null mammary epithelial cells, when transplanted into the cleared fat pads of nude mice, fail to regenerate a functional mammary gland because they cannot differentiate into luminal cells and are unable to undergo branch initiation and elongation (Zhang et al. 2014). FGF2 and FGF10 are identified as stromal ligands that control distinct aspects of mammary ductal branching. In a model of spatiotemporal regulation of branching morphogenesis, FGF10 acts in early stages to direct epithelial migration and branching, whereas FGF2 is responsible for epithelial expansion and duct elongation (Zhang et al. 2014). Consistently, microarray studies where the transcriptome profile of mammary ductal or TEB epithelia is compared to distal stroma from 5-week-old mice reveal a high induction of FGF10 ligand in the stroma (KourosMehr and Werb 2006). 
I. Bernascone et al.

FGF signaling between the developing endoderm and mesoderm is crucial for generating new branch points in the developing lung. FGFR2b is predominantly expressed in the airway epithelium in the developing lung and binds to four known ligands (FGF1, FGF3, FGF7, and FGF10), expressed by mesenchymal cells. Peters et al. showed for the first time that signaling by FGFR2b is required for airway branching and epithelial differentiation in the mammalian lung (Peters et al. 1994). Further evidence came from $F g f r 2$ inactivation in the embryo. Whereas mice null for the Fgfr2 gene die early during embryogenesis, those that are null for the Fgfr $2 b$ isoform but retain $F g f r 2 c$ survive to birth (Arman et al. 1998; De Moerlooze et al. 2000). Mice deficient for Fgfr $2 b$ show agenesis and dysgenesis of multiple organs, including the lungs, indicating that signaling through this receptor is critical for mesenchymal-epithelial interactions during early organogenesis. Several in vitro studies have been performed to investigate the role of FGF ligands in branching morphogenesis in the lung. By culturing lung organs in the presence of FGF10- and FGF7-soaked beads, it has been shown that FGF10 is able to induce elongation of epithelial buds toward the FGF10 source, thus acting as a chemoattractant, whereas FGF7 is able to induce proliferation and dilatation of the epithelial tubule around the bead. These results are clue indicators of the importance of both ligands, FGF10 and FGF7, in inducing branching in early stages of lung development (Park et al. 1998; Lebeche et al. 1999). Consistently, mice deficient for FgflO show multiple organ defects including lung agenesis (Min et al. 1998; Sekine et al. 1999).

Furthermore, FGF signaling in the lung has been coupled to the Shh signaling pathway (Hirashima et al. 2008). The model proposed so far is that the FGF10 ligand secreted by mesenchymal cells signals through FGFR2b on epithelial cells. The activation of FGFR2b induces the expression of Shh, which acts by regulating FGF10 levels in the mesenchyme, thus creating a negative feedback loop (Pepicelli et al. 1998; Chuang and McMahon 2003; Herriges and Morrisey 2014).

\section{CONCLUDING REMARKS}

During development, many of our epithelial cells undergo a series of processes (e.g., proliferation, migration, cell-shape change, and patterning) to give rise to polarized layers of cells that organize to form tubular organs like kidneys, lungs, and mammary glands. Epithelial layers thus function as barriers capable of interacting with the different microenvironments on either side of the epithelium and allowing to perform essential body functions like excretion and gas exchange. Despite the importance of tube information and maintenance in development and disease, our understanding of how tubular organs are established is quite limited. Most of our knowledge about lumen formation, which represents the early phase of tubulogenesis, comes from studies on 3D cell culture models. They show that cell-cell and cell-extracellular matrix interactions are pivotal for the establishment of the apicobasal polarity that precedes the formation and expansion of a single lumen. Studies on invertebrates, such as Drosophila, and vertebrate models, like Xenopus, zebrafish, and mouse, have broadened our understanding of the processes of tubule elongation and branching. The generation and characterization of transgenic and knockout mouse models in the last decades have allowed investigators to identify the signaling routes driving and controlling elongation and branching morphogenesis, but they have not elucidated the intracellular signal transduction pathways yet. Future in vitro and in vivo studies are needed to unveil the downstream target genes of the signaling pathways (i.e., what genes are activated and how the transcriptome changes in response to extracellular signals to drive the branching process). Hopefully, future research will shed light on whether or not the molecular pathways are conserved and whether the final signaling responses are similar between different models/organs. Furthermore, studies on animal models should aim at unraveling the molecular basis of stromal-epithelial interactions, which have been shown to be key events in the tubulogenesis process and that cannot be mimicked by in vitro models. 


\section{ACKNOWLEDGMENTS}

We thank Carmen M. Ruiz-Jarabo for her comments on the manuscript and members of the Martin-Belmonte laboratory for helpful discussions. This work is supported by grants from the Ministerio de Economía y Competitividad (MINECO) (BFU2015-71244-ERC; BFU201452125-REDT; BFU2014-57831), to F.M.-B. M.H. is supported by a MINECO-FPI 2012 PhD fellowship.

\section{REFERENCES}

Adler PN. 2002. Planar signaling and morphogenesis in Drosophila. Dev Cell 2: 525-535.

Akhtar N, Streuli CH. 2013. An integrin-ILK-microtubule network orients cell polarity and lumen formation in glandular epithelium. Nat Cell Biol 15: 17-27.

Alescio T, Cassini A. 1962. Induction in vitro of tracheal buds by pulmonary mesenchyme grafted on tracheal epithelium. J Exp Zool 150: 83-94.

Apodaca G, Gallo LI, Bryant DM. 2012. Role of membrane traffic in the generation of epithelial cell asymmetry. Nat Cell Biol 14: 1235-1243.

Arman E, Haffner-Krausz R, Chen Y, Heath JK, Lonai P. 1998. Targeted disruption of fibroblast growth factor (FGF) receptor 2 suggests a role for FGF signaling in pregastrulation mammalian development. Proc Natl Acad Sci 95: 5082-5087.

Attia L, Schneider J, Yelin R, Schultheiss TM. 2015. Collective cell migration of the nephric duct requires FGF signaling. Dev Dyn 244: 157-167.

Axelrod JD. 2009. Progress and challenges in understanding planar cell polarity signaling. Semin Cell Dev Biol 20: 964-971.

Bagnat M, Cheung ID, Mostov KE, Stainier DY. 2007. Genetic control of single lumen formation in the zebrafish gut. Nat Cell Biol 9: 954-960.

Bedzhov I, Zernicka-Goetz M. 2014. Self-organizing properties of mouse pluripotent cells initiate morphogenesis upon implantation. Cell 156: 1032-1044.

Bradbury JM, Edwards PA, Niemeyer CC, Dale TC. 1995. Wnt-4 expression induces a pregnancy-like growth pattern in reconstituted mammary glands in virgin mice. Dev Biol 170: 553-563.

Bradley PL, Haberman AS, Andrew DJ. 2001. Organ formation in Drosophila: Specification and morphogenesis of the salivary gland. Bioessays 23: 901-911.

Brisken C, Heineman A, Chavarria T, Elenbaas B, Tan J, Dey SK, McMahon JA, McMahon AP, Weinberg RA. 2000. Essential function of Wnt-4 in mammary gland development downstream of progesterone signaling. Genes Dev 14: $650-654$.

Brunskill EW, Park JS, Chung E, Chen F, Magella B, Potter SS. 2014. Single cell dissection of early kidney development: Multilineage priming. Development 141: 30933101.
Bryant D, Mostov K. 2007. Development: Inflationary pressures. Nature 449: 549-550.

Bryant DM, Datta A, Rodriguez-Fraticelli AE, Peranen J, Martin-Belmonte F, Mostov KE. 2010. A molecular network for de novo generation of the apical surface and lumen. Nat Cell Biol 12: 1035-1045.

Bryant DM, Roignot J, Datta A, Overeem AW, Kim M, Yu W, Peng X, Eastburn DJ, Ewald AJ, Werb Z, et al. 2014. A molecular switch for the orientation of epithelial cell polarization. Dev Cell 31: 171-187.

Buhler TA, Dale TC, Kieback C, Humphreys RC, Rosen JM. 1993. Localization and quantification of Wnt-2 gene expression in mouse mammary development. Dev Biol 155: 87-96.

Cancilla B, Ford-Perriss MD, Bertram JF. 1999. Expression and localization of fibroblast growth factors and fibroblast growth factor receptors in the developing rat kidney. Kidney Int 56: 2025-2039.

Castelli M, Boca M, Chiaravalli M, Ramalingam H, Rowe I, Distefano G, Carroll T, Boletta A. 2013. Polycystin-1 binds Par3/aPKC and controls convergent extension during renal tubular morphogenesis. Nat Commun 4: 2658.

Caviglia S, Luschnig S. 2014. Tube fusion: making connections in branched tubular networks. Semin Cell Dev Biol 31: $82-90$.

Celli G, LaRochelle WJ, Mackem S, Sharp R, Merlino G. 1998. Soluble dominant-negative receptor uncovers essential roles for fibroblast growth factors in multi-organ induction and patterning. EMBO J 17: 1642-1655.

Chuang PT, McMahon AP. 2003. Branching morphogenesis of the lung: New molecular insights into an old problem. Trends Cell Biol 13: 86-91.

Ciruna B, Jenny A, Lee D, Mlodzik M, Schier AF. 2006. Planar cell polarity signalling couples cell division and morphogenesis during neurulation. Nature 439: 220224.

Cohen D, Fernandez D, Lazaro-Dieguez F, Musch A. 2011. The serine/threonine kinase Parlb regulates epithelial lumen polarity via IRSp53-mediated cell-ECM signaling. J Cell Biol 192: 525-540.

Costantini F, Kopan R. 2010. Patterning a complex organ: Branching morphogenesis and nephron segmentation in kidney development. Dev Cell 18: 698-712.

Curtin JA, Quint E, Tsipouri V, Arkell RM, Cattanach B, Copp AJ, Henderson DJ, Spurr N, Stanier P, Fisher EM, et al. 2003. Mutation of Celsr1 disrupts planar polarity of inner ear hair cells and causes severe neural tube defects in the mouse. Curr Biol 13: 1129-1133.

Datta A, Bryant DM, Mostov KE. 2011. Molecular regulation of lumen morphogenesis. Curr Biol 21: R126-R136.

De Moerlooze L, Spencer-Dene B, Revest JM, Hajihosseini M, Rosewell I, Dickson C. 2000. An important role for the IIIb isoform of fibroblast growth factor receptor 2 (FGFR2) in mesenchymal-epithelial signalling during mouse organogenesis. Development 127: 483-492.

Denholm B, Skaer H. 2003. Tubulogenesis: A role for the apical extracellular matrix? Curr Biol 13: R909-911.

Devine WP, Lubarsky B, Shaw K, Luschnig S, Messina L, Krasnow MA. 2005. Requirement for chitin biosynthesis 
I. Bernascone et al.

in epithelial tube morphogenesis. Proc Natl Acad Sci 102: 17014-17019.

Dong B, Hannezo E, Hayashi S. 2014. Balance between apical membrane growth and luminal matrix resistance determines epithelial tubule shape. Cell Rep 7: 941-950.

Durdu S, Iskar M, Revenu C, Schieber N, Kunze A, Bork P, Schwab Y, Gilmour D. 2014. Luminal signalling links cell communication to tissue architecture during organogenesis. Nature 515: 120-124.

Eaton S, Martin-Belmonte F. 2014. Cargo sorting in the endocytic pathway: A key regulator of cell polarity and tissue dynamics. Cold Spring Harb Perspect Biol 6: a016899.

Ewald AJ, Brenot A, Duong M, Chan BS, Werb Z. 2008. Collective epithelial migration and cell rearrangements drive mammary branching morphogenesis. Dev Cell 14: $570-581$.

Fanto M, McNeill H. 2004. Planar polarity from flies to vertebrates. J Cell Sci 117: 527-533.

Ferrari A, Veligodskiy A, Berge U, Lucas MS, Kroschewski R. 2008. ROCK-mediated contractility, tight junctions and channels contribute to the conversion of a preapical patch into apical surface during isochoric lumen initiation. J Cell Sci 121: 3649-3663.

Fischer E, Legue E, Doyen A, Nato F, Nicolas JF, Torres V, Yaniv M, Pontoglio M. 2006. Defective planar cell polarity in polycystic kidney disease. Nat Genet 38: 21-23.

Forster D, Luschnig S. 2012. Src42A-dependent polarized cell shape changes mediate epithelial tube elongation in Drosophila. Nat Cell Biol 14: 526-534.

Galvez-Santisteban M, Rodriguez-Fraticelli AE, Bryant DM, Vergarajauregui S, Yasuda T, Banon-Rodriguez I, Bernascone I, Datta A, Spivak N, Young K, et al. 2012. Synaptotagmin-like proteins control the formation of a single apical membrane domain in epithelial cells. Nat Cell Biol 14: 838-849.

Gavin BJ, McMahon AP. 1992. Differential regulation of the Wnt gene family during pregnancy and lactation suggest a role in postnatal development of the mammary gland. Mol Cell Biol 12: 2418-2423.

Germino GG. 2005. Linking cilia to Wnts. Nat Genet 37: $455-457$.

Gillies TE, Cabernard C. 2011. Cell division orientation in animals. Curr Biol 21: R599-R609.

Goodrich LV, Strutt D. 2011. Principles of planar polarity in animal development. Development 138: 1877-1892.

Greene ND, Gerrelli D, Van Straaten HW, Copp AJ. 1998. Abnormalities of floor plate, notochord and somite differentiation in the loop-tail (Lp) mouse: A model of severe neural tube defects. Mech Dev 73: 59-72.

Grobstein C. 1967. Mechanisms of organogenetic tissue interaction. Natl Cancer Inst Monogr 26: 279-299.

Haas P, Gilmour D. 2006. Chemokine signaling mediates self-organizing tissue migration in the zebrafish lateral line. Dev Cell 10: 673-680.

Herriges M, Morrisey EE. 2014. Lung development: Orchestrating the generation and regeneration of a complex organ. Development 141: 502-513.

Herwig L, Blum Y, Krudewig A, Ellertsdottir E, Lenard A, Belting HG, Affolter M. 2011. Distinct cellular mecha- nisms of blood vessel fusion in the zebrafish embryo. Curr Biol 21: 1942-1948.

Hirashima T, Iwasa Y, Morishita Y. 2008. Distance between AER and ZPA is defined by feed-forward loop and is stabilized by their feedback loop in vertebrate limb bud. Bull Math Biol 70: 438-459.

Hogan BL, Kolodziej PA. 2002. Organogenesis: molecular mechanisms of tubulogenesis. Nat Rev Genet 3: 513-523.

Huang YL, Niehrs C. 2014. Polarized Wnt signaling regulates ectodermal cell fate in Xenopus. Dev Cell 29: 250 257.

Humphreys RC, Krajewska M, Krnacik S, Jaeger R, Weiher H, Krajewski S, Reed JC, Rosen JM. 1996. Apoptosis in the terminal endbud of the murine mammary gland: A mechanism of ductal morphogenesis. Development 122: 4013-4022.

Ingman WV, Wyckoff J, Gouon-Evans V, Condeelis J, Pollard JW. 2006. Macrophages promote collagen fibrillogenesis around terminal end buds of the developing mammary gland. Dev Dyn 235: 3222-3229.

Jessen JR, Topczewski J, Bingham S, Sepich DS, Marlow F Chandrasekhar A, Solnica-Krezel L. 2002. Zebrafish trilobite identifies new roles for Strabismus in gastrulation and neuronal movements. Nat Cell Biol 4: 610-615.

Jung AC, Denholm B, Skaer H, Affolter M. 2005. Renal tubule development in Drosophila: A closer look at the cellular level. J Am Soc Nephrol 16: 322-328.

Kamei M, Saunders WB, Bayless KJ, Dye L, Davis GE, Weinstein BM. 2006. Endothelial tubes assemble from intracellular vacuoles in vivo. Nature 442: 453-456.

Karner C, Wharton KA, Carroll TJ. 2006. Apical-basal polarity, Wnt signaling and vertebrate organogenesis. Semin Cell Dev Biol 17: 214-222.

Karner CM, Chirumamilla R, Aoki S, Igarashi P, Wallingford JB, Carroll TJ. 2009. Wnt9b signaling regulates planar cell polarity and kidney tubule morphogenesis. Nat Genet 41: 793-799.

Keller R, Davidson L, Edlund A, Elul T, Ezin M, Shook D, Skoglund P. 2000. Mechanisms of convergence and extension by cell intercalation. Philos Trans $R$ Soc Lond B Biol Sci 355: 897-922.

Kim GH, Her JH, Han JK. 2008. Ryk cooperates with Frizzled 7 to promote Wnt11-mediated endocytosis and is essential for Xenopus laevis convergent extension movements. J Cell Biol 182: 1073-1082.

Kispert A, Vainio S, McMahon AP. 1998. Wnt-4 is a mesenchymal signal for epithelial transformation of metanephric mesenchyme in the developing kidney. Development 125: 4225-4234.

Kouros-Mehr H, Werb Z. 2006. Candidate regulators of mammary branching morphogenesis identified by genome-wide transcript analysis. Dev Dyn 235: 34043412.

Lebeche D, Malpel S, Cardoso WV. 1999. Fibroblast growth factor interactions in the developing lung. Mech Dev 86: $125-136$.

Lecaudey V, Cakan-Akdogan G, Norton WH, Gilmour D. 2008. Dynamic Fgf signaling couples morphogenesis and migration in the zebrafish lateral line primordium. Development 135: 2695-2705. 
Lee JL, Streuli CH. 2014. Integrins and epithelial cell polarity. J Cell Sci 127: 3217-3225.

Li C, Xiao J, Hormi K, Borok Z, Minoo P. 2002. Wnt5a participates in distal lung morphogenesis. Dev Biol 248: 68-81.

Li C, Hu L, Xiao J, Chen H, Li JT, Bellusci S, Delanghe S, Minoo P. 2005. Wnt5a regulates Shh and Fgf10 signaling during lung development. Dev Biol 287: 86-97.

Lienkamp SS, Liu K, Karner CM, Carroll TJ, Ronneberger O, Wallingford JB, Walz G. 2012. Vertebrate kidney tubules elongate using a planar cell polarity-dependent, rosettebased mechanism of convergent extension. Nat Genet 44: 1382-1387.

Lin Y, Zhang S, Rehn M, Itaranta P, Tuukkanen J, Heljasvaara R, Peltoketo H, Pihlajaniemi T, Vainio S. 2001. Induced repatterning of type XVIII collagen expression in ureter bud from kidney to lung type: Association with sonic hedgehog and ectopic surfactant protein C. Development 128: $1573-1585$.

Lu X, Borchers AG, Jolicoeur C, Rayburn H, Baker JC, Tessier-Lavigne M. 2004. PTK7/CCK-4 is a novel regulator of planar cell polarity in vertebrates. Nature 430: 93-98.

Lu P, Ewald AJ, Martin GR, Werb Z. 2008. Genetic mosaic analysis reveals FGF receptor 2 function in terminal end buds during mammary gland branching morphogenesis. Dev Biol 321: 77-87.

Lubarsky B, Krasnow MA. 2003. Tube morphogenesis: Making and shaping biological tubes. Cell 112: 19-28.

Mao Y, Mulvaney J, Zakaria S, Yu T, Morgan KM, Allen S, Basson MA, Francis-West P, Irvine KD. 2011. Characterization of a Dchs1 mutant mouse reveals requirements for Dchs1-Fat4 signaling during mammalian development. Development 138: 947-957.

Marciano DK. 2016. A holey pursuit: Lumen formation in the developing kidney. Pediatr Nephrol 32: 7-20.

Martin-Belmonte F, Mostov K. 2008. Regulation of cell polarity during epithelial morphogenesis. Curr Opin Cell Biol 20: 227-234.

Martin-Belmonte F, Yu W, Rodriguez-Fraticelli AE, Ewald AJ, Werb Z, Alonso MA, Mostov K. 2008. Cell-polarity dynamics controls the mechanism of lumen formation in epithelial morphogenesis. Curr Biol 18: 507-513.

McCaffrey LM, Macara IG. 2011. Epithelial organization, cell polarity and tumorigenesis. Trends Cell Biol 21: 727-735.

Meinhardt A, Eberle D, Tazaki A, Ranga A, Niesche M, Wilsch-Brauninger M, Stec A, Schackert G, Lutolf M, Tanaka EM. 2014. 3D reconstitution of the patterned neural tube from embryonic stem cells. Stem Cell Rep 3: 987-999.

Min H, Danilenko DM, Scully SA, Bolon B, Ring BD, Tarpley JE, DeRose M, Simonet WS. 1998. Fgf-10 is required for both limb and lung development and exhibits striking functional similarity to Drosophila branchless. Genes Dev 12: 3156-3161.

Mucenski ML, Wert SE, Nation JM, Loudy DE, Huelsken J, Birchmeier W, Morrisey EE, Whitsett JA. 2003. $\beta$-Catenin is required for specification of proximal/distal cell fate during lung morphogenesis. J Biol Chem 278: 40231-40238.
Myllymaki SM, Teravainen TP, Manninen A. 2011. Two distinct integrin-mediated mechanisms contribute to apical lumen formation in epithelial cells. PLoS ONE 6: e19453.

Navis A, Bagnat M. 2015. Developing pressures: Fluid forces driving morphogenesis. Curr Opin Genet Dev 32: 24-30.

Naylor S, Smalley MJ, Robertson D, Gusterson BA, Edwards PA, Dale TC. 2000. Retroviral expression of Wnt-1 and Wnt-7b produces different effects in mouse mammary epithelium. J Cell Sci 113: 2129-2138.

O’Brien LE, Jou TS, Pollack AL, Zhang Q, Hansen SH, Yurchenco P, Mostov KE. 2001. Racl orientates epithelial apical polarity through effects on basolateral laminin assembly. Nat Cell Biol 3: 831-838.

Ochoa-Espinosa A, Affolter M. 2012. Branching morphogenesis: From cells to organs and back. Cold Spring Harb Perspect Biol 4: a008243.

Ohuchi H, Hori Y, Yamasaki M, Harada H, Sekine K, Kato S, Itoh N. 2000. FGF10 acts as a major ligand for FGF receptor 2 IIIb in mouse multi-organ development. Biochem Biophys Res Commun 277: 643-649.

Ozturk-Colak A, Moussian B, Araujo SJ, Casanova J. 2016. A feedback mechanism converts individual cell features into a supracellular ECM structure in Drosophila trachea. eLife 5: e09373.

Park WY, Miranda B, Lebeche D, Hashimoto G, Cardoso WV. 1998. FGF-10 is a chemotactic factor for distal epithelial buds during lung development. Dev Biol 201: $125-134$.

Parsa S, Ramasamy SK, De Langhe S, Gupte VV, Haigh JJ, Medina D, Bellusci S. 2008. Terminal end bud maintenance in mammary gland is dependent upon FGFR2b signaling. Dev Biol 317: 121-131.

Pepicelli CV, Lewis PM, McMahon AP. 1998. Sonic hedgehog regulates branching morphogenesis in the mammalian lung. Curr Biol 8: 1083-1086.

Peradziryi H, Tolwinski NS, Borchers A. 2012. The many roles of PTK7: A versatile regulator of cell-cell communication. Arch Biochem Biophys 524: 71-76.

Peters K, Werner S, Liao X, Wert S, Whitsett J, Williams L. 1994. Targeted expression of a dominant negative FGF receptor blocks branching morphogenesis and epithelial differentiation of the mouse lung. EMBO J 13: 32963301.

Pond AC, Bin X, Batts T, Roarty K, Hilsenbeck S, Rosen JM. 2013. Fibroblast growth factor receptor signaling is essential for normal mammary gland development and stem cell function. Stem Cells 31: 178-189.

Qiao J, Uzzo R, Obara-Ishihara T, Degenstein L, Fuchs E, Herzlinger D. 1999. FGF-7 modulates ureteric bud growth and nephron number in the developing kidney. Development 126: 547-554.

Qiao J, Bush KT, Steer DL, Stuart RO, Sakurai H, Wachsman W, Nigam SK. 2001. Multiple fibroblast growth factors support growth of the ureteric bud but have different effects on branching morphogenesis. Mech Dev 109: $123-135$.

Rao TP, Kuhl M. 2010. An updated overview on Wnt signaling pathways: A prelude for more. Circ Res 106: 1798 1806. 
I. Bernascone et al.

Roarty K, Serra R. 2007. Wnt5a is required for proper mammary gland development and TGF- $\beta$-mediated inhibition of ductal growth. Development 134: 3929-3939.

Rodriguez-Boulan E, Macara IG. 2014. Organization and execution of the epithelial polarity programme. Nat Rev Mol Cell Biol 15: 225-242.

Rodriguez-Fraticelli AE, Galvez-Santisteban M, Martin-Belmonte F. 2011. Divide and polarize: Recent advances in the molecular mechanism regulating epithelial tubulogenesis. Curr Opin Cell Biol 23: 638-646.

Rodriguez-Fraticelli AE, Auzan M, Alonso MA, Bornens M, Martin-Belmonte F. 2012. Cell confinement controls cen trosome positioning and lumen initiation during epithelial morphogenesis. J Cell Biol 198: 1011-1023.

Saburi S, Hester I, Fischer E, Pontoglio M, Eremina V, Gessler M, Quaggin SE, Harrison R, Mount R, McNeill H. 2008. Loss of Fat4 disrupts PCP signaling and oriented cell division and leads to cystic kidney disease. Nat Genet 40: $1010-1015$.

Sekine K, Ohuchi H, Fujiwara M, Yamasaki M, Yoshizawa T, Sato T, Yagishita N, Matsui D, Koga Y, Itoh N, et al. 1999. Fgf10 is essential for limb and lung formation. Nat Genet 21: $138-141$.

Shamir ER, Ewald AJ. 2014. Three-dimensional organotypic culture: experimental models of mammalian biology and disease. Nat Rev Mol Cell Biol 15: 647-664.

Sigurbjornsdottir S, Mathew R, Leptin M. 2014. Molecular mechanisms of de novo lumen formation. Nat Rev Mol Cell Biol 15: 665-676.

Stark K, Vainio S, Vassileva G, McMahon AP. 1994. Epithelial transformation of metanephric mesenchyme in the developing kidney regulated by Wnt-4. Nature 372: 679683.

Tada M, Smith JC. 2000. Xwnt11 is a target of Xenopus Brachyury: Regulation of gastrulation movements via $\mathrm{Di}$ shevelled, but not through the canonical Wnt pathway. Development 127: 2227-2238.

Thiery JP, Acloque H, Huang RY, Nieto MA. 2009. Epithelial-mesenchymal transitions in development and disease. Cell 139: 871-890.

Vasilyev A, Liu Y, Mudumana S, Mangos S, Lam PY, Majumdar A, Zhao J, Poon KL, Kondrychyn I, Korzh V, et al. 2009. Collective cell migration drives morphogenesis of the kidney nephron. PLoS Biol 7: e9.

Vasilyev A, Liu Y, Hellman N, Pathak N, Drummond IA. 2012. Mechanical stretch and PI3K signaling link cell migration and proliferation to coordinate epithelial tubule morphogenesis in the zebrafish pronephros. PLoS ONE 7: e39992.

Veeman MT, Slusarski DC, Kaykas A, Louie SH, Moon RT. 2003. Zebrafish prickle, a modulator of noncanonical $\mathrm{Wnt} / \mathrm{Fz}$ signaling, regulates gastrulation movements. Curr Biol 13: 680-685.

Wallingford JB, Harland RM. 2002. Neural tube closure requires Dishevelled-dependent convergent extension of the midline. Development 129: 5815-5825.

Wallingford JB, Mitchell B. 2011. Strange as it may seem: The many links between Wnt signaling, planar cell polarity, and cilia. Genes Dev 25: 201-213.

Wallingford JB, Rowning BA, Vogeli KM, Rothbacher U, Fraser SE, Harland RM. 2000. Dishevelled controls cell polarity during Xenopus gastrulation. Nature 405: 8185.

Wang Y, Nathans J. 2007. Tissue/planar cell polarity in vertebrates: New insights and new questions. Development 134: $647-658$.

Wang J, Hamblet NS, Mark S, Dickinson ME, Brinkman BC, Segil N, Fraser SE, Chen P, Wallingford JB, Wynshaw-Boris A. 2006a. Dishevelled genes mediate a conserved mammalian PCP pathway to regulate convergent extension during neurulation. Development 133: 17671778.

Wang Y, Guo N, Nathans J. 2006b. The role of Frizzled3 and Frizzled6 in neural tube closure and in the planar polarity of inner-ear sensory hair cells. J Neurosci 26: 2147-2156.

Warburton D, Schwarz M, Tefft D, Flores-Delgado G, Anderson KD, Cardoso WV. 2000. The molecular basis of lung morphogenesis. Mech Dev 92: 55-81.

Weber-Hall SJ, Phippard DJ, Niemeyer CC, Dale TC. 1994. Developmental and hormonal regulation of Wnt gene expression in the mouse mammary gland. Differentiation 57: 205-214.

Wu W, Kitamura S, Truong DM, Rieg T, Vallon V, Sakurai H, Bush KT, Vera DR, Ross RS, Nigam SK. 2009. ß1-integrin is required for kidney collecting duct morphogenesis and maintenance of renal function. Am J Physiol Renal Physiol 297: F210-F217.

Yamada M, Udagawa J, Matsumoto A, Hashimoto R, Hatta T, Nishita M, Minami Y, Otani H. 2010. Ror2 is required for midgut elongation during mouse development. Dev Dyn 239: 941-953.

Yamamoto H, Awada C, Hanaki H, Sakane H, Tsujimoto I, Takahashi Y, Takao T, Kikuchi A. 2013. The apical and basolateral secretion of Wnt11 and Wnt3a in polarized epithelial cells is regulated by different mechanisms. J Cell Sci 126: 2931-2943.

Yamamoto H, Awada C, Matsumoto S, Kaneiwa T, Sugimoto T, Takao T, Kikuchi A. 2015. Basolateral secretion of Wnt5a in polarized epithelial cells is required for apical lumen formation. J Cell Sci 128: 1051-1063.

Yamanaka H, Nishida E. 2007. Wnt11 stimulation induces polarized accumulation of Dishevelled at apical adherens junctions through Frizzled7. Genes Cells 12: 961-967.

Yang Z, Zimmerman S, Brakeman PR, Beaudoin GM 3rd, Reichardt LF, Marciano DK. 2013. De novo lumen formation and elongation in the developing nephron: A central role for afadin in apical polarity. Development 140: $1774-1784$.

Yang Z, Zimmerman SE, Tsunezumi J, Braitsch C, Trent C, Bryant DM, Cleaver O, Gonzalez-Manchon C, Marciano DK. 2016. Role of CD34 family members in lumen formation in the developing kidney. Dev Biol 418: 66-74.

Yates LL, Papakrivopoulou J, Long DA, Goggolidou P, Connolly JO, Woolf AS, Dean CH. 2010. The planar cell polarity gene Vangl2 is required for mammalian kidneybranching morphogenesis and glomerular maturation. Hum Mol Genet 19: 4663-4676.

Yu W, Datta A, Leroy P, O’Brien LE, Mak G, Jou TS, Matlin KS, Mostov KE, Zegers MM. 2005. $\beta 1$-integrin orients epithelial polarity via Rac1 and laminin. Mol Biol Cell 16: 433-445. 
Signaling Networks in Epithelial Tube Formation

Yu W, Shewan AM, Brakeman P, Eastburn DJ, Datta A, Bryant DM, Fan QW, Weiss WA, Zegers MM, Mostov KE. 2008. Involvement of RhoA, ROCK I and myosin II in inverted orientation of epithelial polarity. EMBO Rep 9: 923-929.

Yu J, Carroll TJ, Rajagopal J, Kobayashi A, Ren Q, McMahon AP. 2009. AWnt7b-dependent pathway regulates the orientation of epithelial cell division and establishes the cortico-medullary axis of the mammalian kidney. Development 136: 161-171.

Zallen J. 2007. Planar polarity and tissue morphogenesis. Cell 129: 1051-1063.
Zhang X, Martinez D, Koledova Z, Qiao G, Streuli CH, Lu P 2014. FGF ligands of the postnatal mammary stroma regulate distinct aspects of epithelial morphogenesis. $D e$ velopment 141: 3352-3362.

Zhao H, Kegg H, Grady S, Truong HT, Robinson ML, Baum M, Bates CM. 2004. Role of fibroblast growth factor receptors 1 and 2 in the ureteric bud. Dev Biol 276: 403-415.

Zovein AC, Luque A, Turlo KA, Hofmann JJ, Yee KM, Becker MS, Fassler R, Mellman I, Lane TF, Iruela-Arispe ML. 2010. $\beta 1$ integrin establishes endothelial cell polarity and arteriolar lumen formation via a Par3-dependent mechanism. Dev Cell 18: 39-51. 


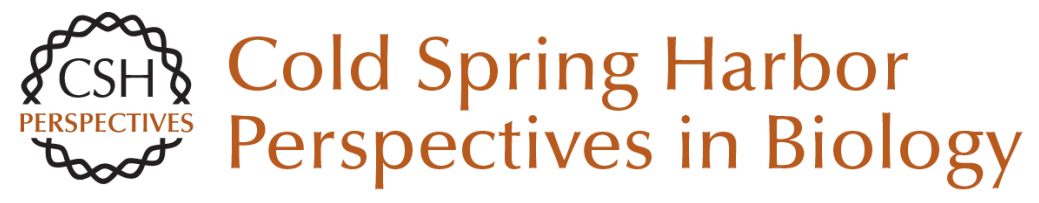

\section{Signaling Networks in Epithelial Tube Formation}

Ilenia Bernascone, Mariam Hachimi and Fernando Martin-Belmonte

Cold Spring Harb Perspect Biol 2017; doi: 10.1101/cshperspect.a027946 originally published online February 28, 2017

\section{Subject Collection Cell Polarity}

Regulation of Cell Polarity by Exocyst-Mediated Trafficking Noemi Polgar and Ben Fogelgren

Phosphoinositides and Membrane Targeting in Cell Polarity Gerald R. Hammond and Yang Hong

Trafficking lon Transporters to the Apical Membrane of Polarized Intestinal Enterocytes Amy Christine Engevik and James R. Goldenring

Signaling Networks in Epithelial Tube Formation Ilenia Bernascone, Mariam Hachimi and Fernando Martin-Belmonte

Making Heads or Tails of It: Cell-Cell Adhesion in Cellular and Supracellular Polarity in Collective Migration Jan-Hendrik Venhuizen and Mirjam M. Zegers

Laminins in Epithelial Cell Polarization: Old Questions in Search of New Answers Karl S. Matlin, Satu-Marja Myllymäki and Aki Manninen

Epithelial Morphogenesis during Liver Development

Naoki Tanimizu and Toshihiro Mitaka

Targeting the Mucosal Barrier: How Pathogens Modulate the Cellular Polarity Network Travis R. Ruch and Joanne N. Engel
The Crumbs3 Polarity Protein Ben Margolis

Microtubule Motors in Establishment of Epithelial Cell Polarity Geri Kreitzer and Monn Monn Myat

Role of Polarity Proteins in the Generation and Organization of Apical Surface Protrusions Gerard Apodaca

Polarized Exocytosis Jingwen Zeng, Shanshan Feng, Bin Wu, et al.

Regulation of Transporters and Channels by Membrane-Trafficking Complexes in Epithelial Cells

Curtis T. Okamoto

Membrane Transport across Polarized Epithelia Maria Daniela Garcia-Castillo, Daniel J.-F. Chinnapen and Wayne I. Lencer

Mechanisms of Cell Polarity-Controlled Epithelial Homeostasis and Immunity in the Intestine Leon J. Klunder, Klaas Nico Faber, Gerard Dijkstra, et al.

The Biology of Ciliary Dynamics Kuo-Shun Hsu, Jen-Zen Chuang and Ching-Hwa Sung

For additional articles in this collection, see http://cshperspectives.cshlp.org/cgi/collection/

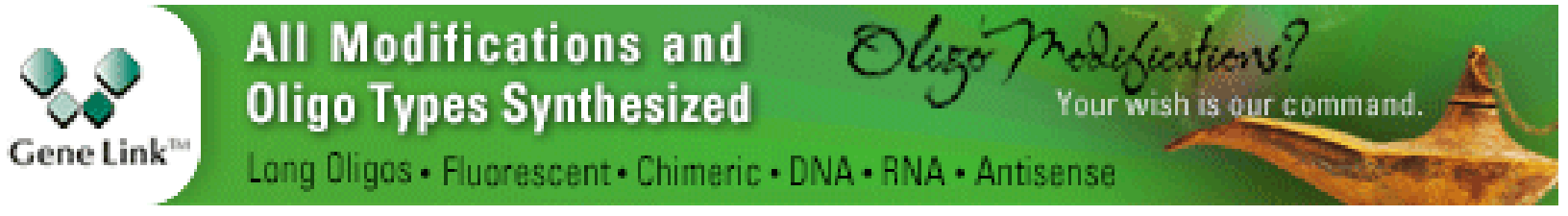

Copyright @ 2017 Cold Spring Harbor Laboratory Press; all rights reserved 